\title{
Revising what readers know: Updating text representations during narrative comprehension
}

\author{
DAVID N. RAPP \\ Northwestern University, Evanston, Illinois \\ AND \\ PANAYiota KendeOU \\ McGill University, Montreal, Quebec, Canada
}

\begin{abstract}
Reading comprehension involves not just encoding information into memory, but also updating and revising what is already known or believed. For example, as narrative plots unfold, readers often must revise the expectations they have constructed from earlier portions of text to successfully comprehend later events. Evidence suggests that such revision is by no means guaranteed. In three experiments, we examined conditions that influence readers' revision of trait-based models for story characters. Trait models are particularly relevant for examining such revision because they demonstrate resistance to change. We specifically assessed whether task instructions and content-driven refutations of earlier information would enhance the likelihood of revision. In Experiment 1, instructions to carefully consider the appropriateness of story outcomes generally facilitated revision. In Experiment 2, we removed those instructions; revision occurred only when refutations included sufficient explanation to suggest that updating was necessary. Experiment 3 further supported the influence of instructions on readers' propensities to revise. These results are informative with respect to the mechanisms that guide readers' moment-by-moment comprehension of unfolding narratives.
\end{abstract}

Readers often encounter information in texts that is suspect, ambiguous, or - in perhaps the most challenging cases - eventually turns out to be inaccurate or outdated (Gerrig, 1993). During narrative comprehension, readers even encounter intentionally misleading information, such as when they learn about characters who turn out to be quite different than originally described. Consider this introduction from the dust jacket of Harry Potter and the Prisoner of Azkaban (Rowling, 1999):

For twelve long years, the dread fortress of Azkaban held an infamous prisoner named Sirius Black. Convicted of killing thirteen people with a single curse, he was said to be the heir apparent to the Dark Lord, Voldemort.

Sirius Black, over the course of the novel, is similarly portrayed as a villainous scoundrel, and Harry takes pains to avoid him. However, Sirius turns out to be Harry's compassionate benefactor; his earlier "evil" behaviors are explained away as critical to Harry's survival. To fully comprehend the plot of the story, readers must revise what they know about Sirius and his actions. In some cases, perhaps surprisingly, readers are not as uniformly successful at this as one might hope.

Prior research has shown that in many situations, readers fail to update memory to include new text information (Johnson \& Seifert, 1994, 1998, 1999; Seifert \& Patalano, 2001). For example, Johnson and Seifert (1994) asked participants to read the transcript of a report on a fire. Early in the transcript, participants read about a possible cause of the fire (i.e., the fire took place in a factory room that likely housed oil paint and pressurized gas cylinders). At a later point in the transcript, some participants read a revision of that information (i.e., that the room was actually empty), whereas others did not. Afterward, they all completed question-and-recall tasks for the transcript. Participants tended to describe the contents of the room as a potential cause of the fire, whether they had read the revised or unrevised version of the transcript. These results suggest that even when later information contradicts earlier material, that earlier material remains available and influential in memory (van Oostendorp \& Bonebakker, 1999). Additional work has demonstrated that such effects are not merely a function of readers ignoring those revisions (Otero \& Kintsch, 1992; Seifert, 2002; Wilkes \& Leatherbarrow, 1988).

Other examples of revision failure have been obtained in more narrative contexts, involving readers' representations of story characters (Guéraud, Harmon, \& Peracchi, 2005). For example, O'Brien, Rizzella, Albrecht, and Halleran (1998) showed that readers' expectations for narrative events were influenced by earlier character descriptions, even if those descriptions were later qualified. In those experiments, participants demonstrated comprehension difficulty when a character's behavior (e.g., "Mary ordered a cheeseburger and fries") contradicted earlier descriptions

D. N. Rapp, rapp@northwestern.edu 
of that character (e.g., "Mary, a health nut, had been a strict vegetarian for ten years"). Participants showed similar difficulty, although to a lesser degree, even when those earlier descriptions were qualified to suggest the character's behavior was nonetheless appropriate (e.g., "Nevertheless, Mary never stuck to her diet when she dined out with friends"). These findings suggest that initially encoded story information continues to exert an influence on comprehension, even when qualified information is provided as a narrative unfolds (Guéraud et al., 2005).

Whereas evidence from the studies mentioned above shows that revision during reading can be a challenge, findings in the extant literature also show that readers can successfully change what they know to reflect new states of affairs in texts (e.g., de Vega, 1995; de Vega, León, \& Diaz, 1996; Diakidoy, Kendeou, \& Ioannides, 2003; Maria \& MacGinitie, 1987). In fact, narrative comprehension often requires careful tracking and subtle revision of what readers have previously read or inferred in a story (Rapp \& Taylor, 2004; Zwaan \& Radvansky, 1998). What factors influence whether readers will change their expectations for story events as narratives unfold? The present project investigated text- and task-driven factors that influence the likelihood that readers successfully or unsuccessfully revise what they know during narrative comprehension.

Reader revision of narrative representations during unfolding text experiences is a specific case of a more general set of comprehension activities that have been labeled updating processes. Updating can be defined as encoding, adding to, or changing representations in memory. This diverse, and admittedly broad, category of processes includes, but is not limited to, the assimilation and accommodation of information (Piaget, 1957), conceptual change learning (e.g., Posner, Strike, Hewson, \& Gertzog, 1982), the correction of misinformation in memory (Johnson \& Seifert, 1998), the reactivation of prior text information during reading (O'Brien et al., 1998), and the evaluation of new information against a current discourse model (Zwaan \& Madden, 2004). Each of these accounts attempts to describe how and when memory changes during various learning experiences. Revision is a specific form of updating - a particularly demanding one, arguably, requiring readers to substantially modify their existing mental representations. Revision therefore involves the activation of representations for what has previously been read, the evaluation of new, possibly contradictory information, and, most importantly, the modification or replacement of those earlier activated representations with the new information. These processes are likely driven by both automatic (Myers \& O'Brien, 1998) and strategic (Singer, Graesser, \& Trabasso, 1994) influences. By this account, examinations of revision during reading can provide useful insight into the nature of updating - and, therefore, learning and comprehension.

Some of the conditions that facilitate successful revision have been emphasized in work on students' misconceptions about scientific principles and complex concepts (e.g., Dole \& Sinatra, 1998; Hynd \& Guzzetti, 1998; Posner et al., 1982; Vosniadou, 2003). Research in the area of conceptual change has demonstrated the utility of refutation texts in helping individuals revise what they know (with what they know defined as strongly held preconceptions relying on their mental representations of the world) (Alvermann \& Hague, 1989; Alvermann, Smith, \& Readence, 1985; Hynd \& Alvermann, 1986). Refutation texts include statements that explicitly refute incorrect beliefs and explain correct principles. Because refutations help students notice discrepancies between what they incorrectly believe and what they should know, such statements are quite useful for instantiating revision in a variety of learning contexts (Diakidoy et al., 2003; Guzzetti, Snyder, Glass, \& Gamas, 1993; Guzzetti, Williams, Skeels, \& Wu, 1997). Refutations are in principle similar to the qualified elaborations used by O'Brien and colleagues (1998) in their work on narrative updating, in that they both suggest that earlier information is potentially inaccurate. They differ, though, in that refutations, unlike qualified elaborations, always attempt to obviate misconceptions rather than to qualify the conditions under which those misconceptions might or might not be viable. In this study, we examine whether refutations are effective at helping readers revise their models of characters.

Besides the content of a refutation, task instructions can also focus students' attention on important material (i.e., information discrepant with their incorrect beliefs), increasing the likelihood that they will revise their misconceptions (e.g., Limon, 2001; Pintrich, Marx, \& Boyle, 1993; Sinatra \& Pintrich, 2003). In reading contexts, task instructions can generally influence text comprehension by focusing readers' attention on particular elements of texts or by making those elements more salient (Jenkins, 1979). For example, when readers are given instructions to anticipate likely future events in stories, they increase their propensities for generating inferences, presumably as a function of increased attentional focus to particular narrative events (e.g., Allbritton, 2004; Calvo, Castillo, \& Schmalhofer, 2006). Thus, instructions may help (or even compel) readers to focus on text qualities, dimensions, or content that qualitatively influences their comprehension of the material (Guzzetti, 1990; Magliano, Trabasso, \& Graesser, 1999; McKoon \& Ratcliff, 1986; van den Broek, Lorch, Linderholm, \& Gustafson, 2001; van den Broek, Rapp, \& Kendeou, 2005). In line with this view, we examined whether instructing readers to focus their attention on the appropriateness of story events might also increase the likelihood of revision.

To assess the influences of task instructions and text content on narrative comprehension, we presented participants with stories that described and then refuted characteristics of story characters. Narrative stimuli like these are particularly useful for investigating revision, because there is a considerable literature demonstrating that the initial impressions we derive from observing and reading about people hold a privileged status in memory. Evidence suggests that such impressions are formed quickly and held strongly (Anderson, 1965; Asch, 1946; Borkenau \& Liebler, 1992), sometimes only on the basis of individual instances of behavior encoded during a single text experience (Newman \& Uleman, 1990; Uleman, Hon, Roman, \& Moskowitz, 1996; Winter \& Uleman, 1984). Indeed, readers tend to generate inferences about story characters from brief text descriptions and to expect those characters' 
behaviors to remain consistent over time (Gernsbacher, Goldsmith, \& Robertson, 1992; Gernsbacher, Hallada, \& Robertson, 1998; Peracchi \& O’Brien, 2004).

The present study sought to extend this work by assessing the degree to which readers might successfully or unsuccessfully revise their models of characters on the basis of subsequent information. Previous research is quite useful with respect to this goal, in providing evidence that readers develop trait models that influence expectations about future narrative events. For example, Rapp, Gerrig, and Prentice (2001) asked participants to read about characters in stories that provided either behavioral evidence for a particular trait (e.g., "Albert's shoes were buried under old candy wrappers, crumpled magazines, and some dirty laundry" for the trait sloppy) or control information unrelated to a trait. Each story included a second scenario in which the main character could behave in a manner either consistent or inconsistent with that trait. At the conclusion of this second scenario, participants read an outcome that was either consistent or inconsistent with the potentially mentioned trait. It is worth noting that the traits were never explicitly mentioned in the stories, thereby providing a critical test of whether readers would infer trait models on the basis of behavioral descriptions and use those models to predict future narrative events. In Experiment 1, participants judged the appropriateness of story outcomes, and were more likely to agree with trait-consistent than with traitinconsistent outcomes after reading behavioral evidence for the relevant trait; if they read control contexts, participants were equally likely to agree with either outcome. In a follow-up experiment, reading times to story outcomes were recorded to examine whether participants would rely on trait models without being asked to complete an explicit judgment task. The results converged with Experiment 1 . Participants took longer to read trait-inconsistent than to read trait-consistent outcomes if they had been presented with behavioral evidence for the relevant trait; following control contexts, participants took an equivalent amount of time to read either outcome. On the basis of the results, Rapp et al. argued that readers swiftly build trait models for characters as a necessary part of understanding the causal sequence of events in stories.

Again, results like these are critical to the present investigation of revision, in that they show that readers build trait models that foster strongly held expectations for future narrative events. Importantly, follow-up experiences in general often fail to change our first impressions of others whether personally experienced or generated from text descriptions (Anderson, 1965; Fleming \& Arrowood, 1979; Hendrick \& Constantini, 1970; Kunda \& Thagard, 1996). Although there is some evidence that particular cues can influence the likelihood of impression revision (e.g., Reeder \& Coovert, 1986; Ybarra, Schaberg, \& Keiper, 1999), under many circumstances our initial impressions of others are remarkably impervious to intervention (Hertel, 1985; Ybarra, 2001). Thus, identifying the conditions that might foster revision of readers' trait models would have important implications for understanding processes of updating, both for text comprehension research as well as for work in a variety of other psychological domains.
In the present study, participants read narratives describing characters engaged in various activities. Each story included a description of a character's behavior designed to imply a particular trait. For example, consider the following story:

Over the weekend Travis decided to go swing dancing. MTV had been promoting swing boogie as the hot new fad. On Saturday night Travis went to a trendy swing club. It was not very crowded, so it was quite comfortable. He eagerly stepped onto the dance floor. Travis spent the whole evening tripping over his girlfriend's feet.

The final sentence is designed to lead readers to believe that Travis is clumsy (Rapp et al., 2001). Readers were then provided with one of several types of confirmation or refutation-based statements about that potential trait inference. For example, a confirmatory statement would support the view that Travis is clumsy:

He was having trouble keeping his balance while he was performing dance moves.

In contrast, a simple refutation might call that earlier information - and hence a trait model - into question, but nevertheless lack sufficient supporting information to warrant revision:

He always had such excellent balance, so his failure was disappointing to them.

A refutation of this type may fail to exert the intended impact because it lacks a causal explanation of why the earlier information is inappropriate for generating future character predictions. Consider instead a refutation that includes this form of necessary explanation:

He always had such excellent balance, but the floor had just been waxed.

We predicted that refutation statements would likely engender revision of readers' previously encoded trait models, if such statements included causal explanations of why earlier information was incorrect. Previous work has suggested that such explanations may help readers detect that a correction is necessary for comprehension (Johnson \& Seifert, 1994). In this example, knowing that the floor was the situational cause of Travis's plight might obviate the belief that he is clumsy. Thus, an alternative causal explanation may be effective at supplanting a previous one, given readers' predilections for tracking the causal sequences in narratives (Trabasso \& van den Broek, 1985).

We also assessed whether task instructions would additionally influence readers' propensities to revise what they know. In Experiment 1, participants were asked to explicitly judge the likelihood of characters' future behaviors. We expected these instructions to increase the likelihood that readers would readily notice discrepancies in character descriptions; noticing such discrepancies should increase the likelihood of revision. In Experiment 2, we eliminated the instructions and measured reading times to story outcomes as an index of whether readers revised their trait models 
spontaneously. Our hypothesis was that revision would be more likely in cases for which refutations suggested such activity was necessary (i.e., following refutations that included sufficient causal explanation as to why an earlier model would be incorrect). In Experiment 3, we reintroduced instructions but did not require participants to explicitly judge the appropriateness of story outcomes, to further test the combinatorial effects of task instructions and refutations on readers' spontaneous revision of trait models.

\section{EXPERIMENT 1}

In Experiment 1, participants read stories that included behavioral evidence for particular traits. This information was (1) supported with an additional statement, (2) refuted in a nonexplanatory way as incorrect, or (3) refuted with an explanation of why an incorrect interpretation of the behavioral evidence was possible. A fourth context for each story replaced the behavioral evidence with statements unrelated to any particular trait, serving as a control. At the end of each story, participants were presented with one of two outcomes and were asked to indicate whether that outcome described what they felt would happen next in the story. These explicit instructions were included to encourage readers to carefully track unfolding plot and characters (Allbritton, 2004; Rapp et al., 2001; Rapp \& Gerrig, 2002, 2006). The outcome presented was either (1) consistent with the trait implied by the behavioral evidence, or (2) inconsistent with the trait implied by the behavioral evidence. This allowed us to assess the degree to which particular refutations might change readers' expectations of how characters would behave.

We made several predictions with respect to this experiment. First, we predicted that readers would construct trait models after reading behavioral descriptions. In that respect, trait and control contexts were intended as a conceptual replication of Rapp et al. (2001), and as baseline evidence that readers encode trait models if character descriptions are available. Evidence consistent with this view would be obtained if readers were more likely to agree with trait-consistent than with trait-inconsistent outcomes following trait contexts but showed no preference for a particular outcome following control contexts. Second, we predicted that the explicit instructions would lead readers to focus attention on the developing events in the stories. Such focus should increase the likelihood that participants revise their models, to some degree, when they encounter contradictory information. Thus, stories containing both simple refutations and refutations with explanations should lead readers to agree more with trait-inconsistent than with trait-consistent outcomes, in direct contrast with the results expected as a function of trait contexts.

\footnotetext{
Method

Participants. Sixty-four University of Minnesota undergraduates, all native speakers of English, participated in this study for course credit.

Apparatus. The experiments used four Pentium 4 PC computers running Superlab software to record responses. Participants sat in front of a Dell color monitor with their hands on the keyboard. They used buttons on the keyboard to provide their responses. Sentences
}

were presented in the center of the screen in standard uppercase and lowercase type. Superlab software recorded participants' responses, including the particular keys pressed during the task and reading latencies for each sentence. These latencies were recorded as the time interval, in milliseconds, from a sentence's presentation onscreen to a participant's press of the NEXT key.

Materials. We used the stories from Rapp et al. (2001), with the modifications described below. Those original stories were normed by Rapp et al. to ensure that particular trait models would be constructed as a function of the behavioral evidence provided. The 24 stories included 12 with negative personality traits (e.g., sloppy, clumsy) and 12 with positive traits (e.g., courteous, generous). We maintained these features, and any modifications we made did not alter the underlying plots described in the stories.

Each story consisted of two seven-sentence episodes (see the Appendix for an example). There were four possible contexts for each first episode, which were identical except for the final two sentences. These last two sentences constituted the different story contexts that participants read in the experiment. Across trait, simple refutation, and refutation with explanation contexts, the first sentence of the pair (sentence 6) was always the same; this sentence provided behavioral evidence that suggested that the story's protagonist possessed a particular trait. The second sentence of this pair (sentence 7, not a component of Rapp et al.'s stimuli), however, was different across the three contexts. In the trait context, this sentence provided further support for the certainty of the trait without providing any explicit mention of the trait. In the simple refutation context, this sentence suggested that any trait inference would be incorrect without any explanation as to why. In the refutation with explanation context, this sentence provided an explanation for earlier behavior inconsistent with a potential trait inference; these explanations included references to situational rather than to dispositional causes, or statements suggesting that the character had changed in ways that no longer causally afforded such inferences. We also constructed control contexts in which the final sentence pair was entirely different; in control contexts, sentences 6 and 7 continued the narrative without focusing on any trait information relevant to the story outcomes. Within each story, we equated the number of words in the final sentence pair of each of the contexts $(M=27.80$ words per pair across all stories with 13.38 words for sentence 6 and 14.42 words for sentence 7 ).

The second episode immediately followed the first and described a situation to which an inferred trait could potentially apply. This second episode was identical for all four contexts. For each of the stories we wrote two outcome sentences to follow episode 2; one outcome was consistent and the other inconsistent with the trait suggested by sentence 6 (in the trait, simple refutation, and refutation with explanation contexts) of the first episode. These outcomes described an action performed or failed to be performed by the protagonist of the story. Within each story, we equated the number of words in the two outcomes ( $M=10.29$ words per outcome across all stories). Each story, including both episodes and an outcome, was 13 sentences long.

We also wrote 12 filler and 3 practice stories that included outcomes not directly related in any way to traits; in this sense, they were similar to control contexts. Filler and practice stories were also 13 sentences long. There was only one version of each filler and practice item. Finally, we wrote a single comprehension question for each experimental, filler, and practice story.

Design. There were 8 versions of each of the 24 stories, in a 4 (story context: trait, control, simple refutation, or refutation with explanation) $\times 2$ (outcome: trait-consistent or trait-inconsistent) within-participants design. Using a Latin square, we constructed eight lists of stories, so that each story appeared in a different version on each list. Thus, each participant read one list of 24 stories in a different random order. Additionally, comprehension questions for the experimental and filler stories were counterbalanced so that each list contained 18 questions requiring YES responses and 18 questions requiring NO responses. 
Procedure. To become familiar with the task and keyboard controls, participants began with three practice stories. At the beginning of each story, the words "Press NEXT for the next story" appeared on the computer screen. Participants pressed the "A" key, labeled NEXT, to begin the story. The first sentence of a story then appeared; after reading it, participants pressed the "A" key to advance to the next sentence. This response was repeated for each sentence in the stories. After participants had read the final sentence of a story, a beep sounded and an outcome sentence appeared. Participants were asked to decide whether the outcome made sense given the story. They were specifically instructed as follows: "It will be your job to decide whether you think this sentence accurately describes what you feel would happen next in the story." Participants indicated YES (i.e., "I agree [this would happen next]" or NO (i.e., "I disagree [that this would happen next]") by pressing " $\mathrm{J}$ " or "K" on the keyboard. After participants made this decision, another beep sounded and the string “***** QUESTION $* * * * *$ "was displayed. This was replaced after $1,000 \mathrm{msec}$ by a comprehension question, and participants pressed either the YES (i.e., "Yes, that is true"; "J") or NO (i.e., "No, that is false"; "K") key in response to the question. There was no time limit for responding to either the judgment task or comprehension question.

\section{Results and Discussion}

To assess the reliability of the results in our experiments, we conducted analyses with both participants $\left(F_{1}\right)$ and items $\left(F_{2}\right)$ as random variables. Table 1 presents the mean agreement rates from Experiment 1. For our analyses we eliminated decision times falling more than 2.5 SDs above the mean for each participant (de Vega et al., 1996). This resulted in a loss of $1.74 \%$ of the data.

We predicted that participants' decisions about the likelihood of outcomes would be informed by the prior contexts in the stories. Support for this view was obtained with a significant interaction between story context and outcome $\left[F_{1}(3,189)=57.04, M S_{\mathrm{e}}=.29, p<.001\right.$; $\left.F_{2}(3,69)=24.96, M S_{\mathrm{e}}=.31, p<.001\right]$; no main effects were significant (all $F \mathrm{~s}<3.0$ ). To test our predictions against particular story contexts, we conducted planned contrasts for each condition. For trait contexts, participants were more likely to agree with trait-consistent than with trait-inconsistent outcomes [a 54.9 percentage point difference: $F_{1}(1,63)=188.25, M S_{\mathrm{e}}=.41, p<.001 ; F_{2}(1,23)=$ $\left.73.31, M S_{\mathrm{e}}=.49, p<.001\right]$; for control contexts lacking trait information, participants did not prefer either outcome (a nonsignificant 2.1 percentage point difference: both $F \mathrm{~s}<1)$. This supports the view that readers encode and use trait models to make judgments about story outcomes. We also predicted that, given the nature of the task instructions, readers would revise their models of charac- ters following both simple refutations and refutations with explanations. Following simple refutation contexts, readers were more likely to agree with trait-inconsistent than with trait-consistent outcomes, significant by participants only [a 10.1 percentage point difference: $F_{1}(1,63)=5.07$, $\left.M S_{\mathrm{e}}=0.54, p<.05 ; F_{2}<1\right]$. More impressively, following refutation with explanation contexts, participants were even more likely to agree with trait-inconsistent than with trait-consistent outcomes [a 25.5 percentage point difference: $F_{1}(1,63)=26.99, M S_{\mathrm{e}}=0.61, p<.001 ; F_{2}(1,23)=$ $\left.7.31, M S_{\mathrm{e}}=.01, p<.05\right]$.

The difference scores between trait-consistent and traitinconsistent story outcomes that we have just described also provide an index for assessing agreement rate change as a function of story context (see Table 1). Using these scores, we conducted planned comparisons specifically to examine whether refutations that included explanations were more effective than simple refutations. A larger difference score is indicative of stronger expectations for a particular outcome, whereas a smaller difference score suggests that participants considered both outcomes plausible. First, though, we compared difference scores for each refutation context with those for trait contexts as an additional test of the utility of refutations in general. Indeed, the $55 \%$ difference for trait contexts was different from that obtained for simple refutation $\left[F_{1}(1,63)=\right.$ $97.14, M S_{\mathrm{e}}=0.28, p<.001 ; F_{2}(1,23)=37.11, M S_{\mathrm{e}}=$ $0.27, p<.05]$ and for refutation with explanation contexts $\left[F_{1}(1,63)=192.17, M S_{\mathrm{e}}=0.22, p<.001 ; F_{2}(1,23)=\right.$ $\left.62.19, M S_{\mathrm{e}}=0.26, p<.001\right]$. Both types of refutation led to revision, as compared with the baseline trait contexts. Second, we compared the effectiveness of each refutation type. The $26 \%$ agreement difference for refutation with explanation contexts was larger than the $10 \%$ difference for simple refutation contexts, significant by participants and marginal by items $\left[F_{1}(1,63)=4.64, M S_{\mathrm{e}}=0.33, p<\right.$ $\left..05 ; F_{2}(1,23)=3.47, M S_{\mathrm{e}}=0.22, p=.075\right]$. This suggests that refutations that included explanations were more effective at inducing revision than were simple refutations. Third, we compared the difference scores to zero (equivalent to no observable difference in expectations for a particular outcome), to examine the magnitude of change in participants' expectations. The analyses were significant for the trait comparison $\left[F_{1}(1,63)=187.73, M S_{\mathrm{e}}=0.10\right.$, $\left.p<.001 ; F_{2}(1,23)=81.00, M S_{\mathrm{e}}=0.09, p<.001\right]$, the refutation with explanation comparison $\left[F_{1}(1,63)=25.98\right.$, $M S_{\mathrm{e}}=0.16, p<.001 ; F_{2}(1,23)=7.26, M S_{\mathrm{e}}=0.25, p<$

Table 1

Agreement Rates (Percent Yes Responses), With Standard Deviations, in Experiment 1

\begin{tabular}{|c|c|c|c|c|c|c|c|c|}
\hline \multirow[b]{3}{*}{ Outcome } & \multicolumn{8}{|c|}{ Story Context } \\
\hline & \multicolumn{2}{|c|}{$\begin{array}{c}\text { Trait } \\
\text { Context }\end{array}$} & \multicolumn{2}{|c|}{$\begin{array}{c}\text { Simple } \\
\text { Refutation }\end{array}$} & \multicolumn{2}{|c|}{$\begin{array}{c}\text { Refutation }+ \\
\text { Explanation }\end{array}$} & \multicolumn{2}{|c|}{$\begin{array}{l}\text { Control } \\
\text { Context }\end{array}$} \\
\hline & $\%$ Yes & $S D$ & $\%$ Yes & $S D$ & $\%$ Yes & $S D$ & $\%$ Yes & $S D$ \\
\hline Trait consistent & 78.1 & 23.9 & 43.5 & 28.3 & 38.5 & 32.6 & 55.2 & 33.6 \\
\hline Trait inconsistent & 23.2 & 26.0 & 53.6 & 28.9 & 64.0 & 31.0 & 57.3 & 32.7 \\
\hline Mean & 50.7 & & 48.6 & & 51.3 & & 56.3 & \\
\hline Difference score & 54.9 & & -10.1 & & -25.5 & & -2.1 & \\
\hline
\end{tabular}

Note-Difference scores were computed by subtracting trait-inconsistent agreement rates from trait-consistent agreement rates. 
$.05]$, and the simple refutation comparison [by participants only: $\left.F_{1}(1,63)=4.71, M S_{\mathrm{e}}=0.14, p<.05 ; F_{2}<1\right]$, but not for the control comparison (both $F_{\mathrm{S}}<1$ ).

Finally, we were also interested in whether readers noticed a discrepancy between the contradictory information provided by refutations and the preceding trait evidence. The effectiveness of a refutation is, at least in part, a function of readers detecting such discrepancies. To assess this issue, we analyzed reading times for sentence 7 (see Table 2). Of course, the content of this sentence depended on the story context condition (although they were equated for length within items); nevertheless, this analysis provides at least preliminary insight into whether readers may have become aware of any incongruities in what they read. We observed only a main effect of story context $\left[F_{1}(3,189)=16.94, M S_{\mathrm{e}}=419,042\right.$, $\left.p<.001 ; F_{2}(3,69)=3.79, M S_{\mathrm{e}}=757,050, p<.05\right]$. Planned contrasts for sentence 7 showed no differences in reading times between trait and control contexts, and no differences between simple refutation and refutation with explanation contexts (all $F \mathrm{~s}<1$ ). However, these contrasts also showed that participants took longer to read sentence 7 when it provided any form of refutation than when it did not. Participants took longer to read simple refutation contexts than to read trait contexts [a 398-msec difference: $F_{1}(1,63)=15.13, M S_{\mathrm{e}}=668,913, p<.001$; $\left.F_{2}(1,23)=6.43, M S_{\mathrm{e}}=591,279, p<.05\right]$ and control contexts [a 311-msec difference: $F_{1}(1,63)=15.95, M S_{\mathrm{e}}=$ $348,596, p<.001 ; F_{2}(1,23)=4.26, M S_{\mathrm{e}}=623,582, p<$ $.05]$. Similarly, participants took longer to read refutation with explanation contexts than to read trait contexts [a 487-msec difference: $F_{1}(1,63)=47.29, M S_{\mathrm{e}}=320,536$, $\left.p<.001 ; F_{2}(1,23)=5.48, M S_{\mathrm{e}}=1,081,158, p<.05\right]$ and control contexts [a 400-msec difference: $F_{1}(1,63)=$ $38.82, M S_{\mathrm{e}}=262,092, p<.001 ; F_{2}(1,23)=4.53, M S_{\mathrm{e}}=$ $986,509, p<.05]$. In sum, participants appeared to notice discrepancies between initial trait evidence and refutations; such noticing may have been a function of the coherence break between the previous behavioral description and the refutation (e.g., Albrecht \& O'Brien, 1993).

These results support our predictions, and in general support the notion that, when given instructions to explicitly judge the appropriateness of outcomes, readers revised trait models. First, when provided with evidence for a character trait, readers generated expectations for future behavior in line with that information, replicating the Rapp et al. (2001) findings. With trait contexts, participants preferred outcomes consistent with their trait models in contrast to outcomes inconsistent with them; with control contexts, participants had no preference for a particular story outcome. The present experiment extends this work by also including instances in which behavioral evidence was immediately followed by a refutation. Readers appeared to revise their models of characters to reflect new expectations as a function of those refutations. After refutations, participants tended to agree more with trait-inconsistent outcomes than with trait-consistent outcomes. Importantly, this effect was most robust for cases in which readers read refutations that included explanations as to why a trait inference may have been inappropriate or hasty.

Readers also took longer to read statements that immediately refuted potential traits than to read statements that did not. This suggests that readers noticed the discrepancies provided by the refutations. Detecting these contradictions may have served as an additional influence on readers' propensities to revise. However, we have no way of knowing, on the basis of these results, whether readers would have been as likely to notice those contradictions without instruction to carefully consider the unfolding story events. In fact, given that readers successfully revised even with simple refutations, it is important to consider whether typically observed revision failures would recur when such instructions were omitted. In Experiment 2 we addressed this issue by investigating the conditions under which readers are more or less likely to undergo spontaneous revision.

\section{EXPERIMENT 2}

In this experiment, we used the same stories and experimental conditions from Experiment 1 with a minor but important change: The outcome sentences were now incorporated directly into the stories, allowing us to measure reading times for those sentences without an explicit judgment component.

Reading times are sensitive to the consistency between early text events and events presented later in the text (the inconsistency effect; e.g., Albrecht \& O'Brien, 1993; Cook, Halleran, \& O'Brien, 1998; O'Brien et al., 1998). For example, reading times for sentences that contradict previous information in a text are slower than they are for sentences consistent with that previous information. In fact, readers take longer to read outcomes describing behaviors that are inconsistent, as compared with consistent, with their expectations for character behavior (Peracchi

Table 2

Mean Reading Times (in Milliseconds), With Standard Deviations, for Story Context Sentence 7 in Experiments 1, 2, and 3

\begin{tabular}{|c|c|c|c|c|c|c|c|c|}
\hline & \multicolumn{8}{|c|}{ Story Context } \\
\hline & \multicolumn{2}{|c|}{$\begin{array}{c}\text { Trait } \\
\text { Context }\end{array}$} & \multicolumn{2}{|c|}{$\begin{array}{c}\text { Simple } \\
\text { Refutation }\end{array}$} & \multicolumn{2}{|c|}{$\begin{array}{c}\text { Refutation }+ \\
\text { Explanation }\end{array}$} & \multicolumn{2}{|c|}{$\begin{array}{l}\text { Control } \\
\text { Context }\end{array}$} \\
\hline & $M$ & $S D$ & $M$ & $S D$ & $M$ & $S D$ & $M$ & $S D$ \\
\hline Experiment 1 & 3,202 & 1,053 & 3,600 & 1,027 & 3,689 & 1,000 & 3,290 & 1,049 \\
\hline Experiment 2 & 3,157 & 1,000 & 3,495 & 1,049 & 3,654 & 1,173 & 3,363 & 1,078 \\
\hline Experiment 3 & 3,224 & 1,064 & 3,735 & 1,181 & 3,795 & 1,162 & 3,400 & 1,292 \\
\hline Mean & 3,195 & & 3,610 & & 3,713 & & 3,351 & \\
\hline
\end{tabular}


Table 3

Mean Reading Times (in Milliseconds), With Standard Deviations, for

Outcome Sentences in Experiment 2

\begin{tabular}{|c|c|c|c|c|c|c|c|c|}
\hline \multirow[b]{3}{*}{ Outcome } & \multicolumn{8}{|c|}{ Story Context } \\
\hline & \multicolumn{2}{|c|}{$\begin{array}{c}\text { Trait } \\
\text { Context }\end{array}$} & \multicolumn{2}{|c|}{$\begin{array}{c}\text { Simple } \\
\text { Refutation }\end{array}$} & \multicolumn{2}{|c|}{$\begin{array}{l}\text { Refutation }+ \\
\text { Explanation }\end{array}$} & \multicolumn{2}{|c|}{$\begin{array}{l}\text { Control } \\
\text { Context }\end{array}$} \\
\hline & $M$ & $S D$ & $M$ & $S D$ & $M$ & $S D$ & $M$ & $S D$ \\
\hline Trait consistent & 2,139 & 631 & 2,133 & 584 & 2,227 & 698 & 2,150 & 627 \\
\hline Trait inconsistent & 2,284 & 707 & 2,225 & 539 & 2,112 & 646 & 2,209 & 629 \\
\hline Mean & 2,212 & & 2,179 & & 2,170 & & 2,180 & \\
\hline Difference score & -145 & & -92 & & 115 & & -59 & \\
\hline
\end{tabular}

Note-Difference scores were computed by subtracting trait-inconsistent reading times

from trait-consistent reading times.

\& O’Brien, 2004; Rapp et al., 2001). Reading times are therefore a metric of readers' difficulty integrating what they have read and inferred into their developing memory representations. In the context of the present experiment, reading times can provide insight into whether participants spontaneously revised (i.e., in the absence of explicit instructions) trait models following refutations.

Our predictions were as follows: first, that reading times would reflect expectations that characters behave in traitconsistent ways. Following trait contexts, reading times for trait-inconsistent outcomes should be longer than for trait-consistent outcomes. Following control contexts that do not set up trait-based expectations, a similar difference should not be obtained. Second, we predicted that readers would spontaneously revise their models when evidence suggested that it was necessary to do so. Thus, following refutations with explanations, we expected that readers would spend more time reading trait-consistent outcomes than reading (previously) trait-inconsistent outcomes; in other words, reading time patterns for outcomes should switch if the refutation is effective at instantiating revision. Because participants would not receive explicit instructions to carefully consider events, these revision patterns should be restricted to stories containing refutations with relevant explanations, and not obtain for stories containing simple refutations lacking any causal explanation.

\section{Method}

Participants. Sixty-four University of Minnesota undergraduates, all native speakers of English, and none of whom had participated in Experiment 1, completed this study for course credit.

Apparatus. The apparatus was identical to that used in Experiment 1 .

Materials and Design. We used the same stories, outcome sentences, comprehension questions, and fillers as in Experiment 1 (see the Appendix for an example). The design used a Latin square to distribute items in a fashion identical to that used in Experiment 1.

Procedure. The procedure was identical to Experiment 1, with the following modifications: We removed the explicit-judgment task and instead asked participants to read each story, think of a title for the story following the outcome sentence, and then answer a comprehension question. Participants pressed the NEXT key to progress through the stories. After pressing the NEXT key following the outcome sentence, a beep sounded from the computer and a prompt read “*** THINK OF A TITLE FOR THE STORY ***” (cf. Rapp \& Gerrig, 2002; Rapp et al., 2001). We included this task so participants would pay appropriate attention while reading each story, given the lack of an explicit judgment task (see Rapp \& Gerrig, 2006, for discussion). Participants were never asked to provide the title. After participants pressed the NEXT key (to signal that they had thought of a title), another beep followed and the string “***** QUESTION * $* * * *$ was displayed. As in Experiment 1, this string was replaced after $1,000 \mathrm{msec}$ by a comprehension question, and there was no time limit to respond to the question.

\section{Results and Discussion}

Table 3 presents the mean reading times for outcome sentences in Experiment 2. As with Experiment 1, we eliminated reading times falling more than $2.5 \mathrm{SDs}$ above the mean for each participant, resulting in a loss of $3.66 \%$ of the data.

We predicted that participants' reading times for story outcomes would be influenced by story contexts. This interaction was significant by participants and marginal by items $\left[F_{1}(3,189)=3.48, M S_{\mathrm{e}}=116,327, p<.05 ; F_{2}(3,69)=\right.$ $\left.2.30, M S_{\mathrm{e}}=62,997, p=.085\right]$; no main effects were significant (all $F \mathrm{~s}<2$ ). We conducted planned comparisons for each condition to examine outcome reading times as a function of story contexts. Following trait contexts, participants took $145 \mathrm{msec}$ longer to read trait-inconsistent than to read trait-consistent outcomes, significant by participants and marginal by items $\left[F_{1}(1,63)=4.54, M S_{\mathrm{e}}=252,614\right.$, $\left.p<.05 ; F_{2}(1,23)=2.87, M S_{\mathrm{e}}=150,587, p=.10\right]$. Following control contexts containing no trait information, this difference was only $59 \mathrm{msec}$ and not significant (both $F_{\mathrm{S}}<1$ ). This pattern provides evidence that readers encode and apply trait models during moment-by-moment reading. But to what degree do refutations lead readers to revise those models? Following simple refutation contexts, participants still took longer to read trait-inconsistent than to read trait-consistent outcomes, although this 92-msec difference was not significant $\left[F_{1}(1,63)=2.57, p>.10\right.$; $\left.F_{2}<1\right]$. Note that the direction of this pattern is similar to that obtained in trait contexts. In contrast, for refutation with explanation contexts, this reading-time pattern was reversed. Participants now took $115 \mathrm{msec}$ longer to read trait-consistent than to read trait-inconsistent outcomes, significant by participants only $\left[F_{1}(1,63)=3.99, M S_{\mathrm{e}}=\right.$ 211,321, $\left.p<.05 ; F_{2}<1\right]$.

As with Experiment 1, we compared the difference scores for outcomes as a function of story context to test the effectiveness of the refutations (see Table 3 ). The 145-msec difference for trait contexts was different from the $115-\mathrm{msec}$ difference for refutation with explanation contexts $\left[F_{1}(1,63)=8.24, M S_{\mathrm{e}}=523,180, p<.01\right.$; $\left.F_{2}(1,23)=5.25, M S_{\mathrm{e}}=289,150, p<.05\right]$. In contrast, 
the 92-msec difference for simple refutation contexts was not significantly different from the trait context difference (both $F_{\mathrm{S}}<1$ ). A direct comparison of the difference scores between simple refutation and refutation with explanation contexts was significant by participants and marginal by items $\left[F_{1}(1,63)=8.64, M S_{\mathrm{e}}=177,241\right.$, $\left.p<.01 ; F_{2}(1,23)=3.73, M S_{\mathrm{e}}=274,150, p=.066\right]$. Participants appeared to revise their trait-based expectations after reading refutations that included explanations, but not after reading simple refutations. The differences compared against zero were significant for both the refutation-with-explanation comparison [by participants only: $\left.F_{1}(1,63)=3.99, M S_{\mathrm{e}}=211,321, p<.05 ; F_{2}<1.7\right]$ and the trait comparison [by participants only: $F_{1}(1,63)=$ $\left.4.54, M S_{\mathrm{e}}=295,051, p<.05 ; F_{2}<2\right]$, but not for the simple refutation or control comparisons (all $F \mathrm{~s}<2.6$ ).

Finally, we analyzed reading times for sentence 7 in episode 1 as a measure of whether readers noticed the refutation-based discrepancies (see Table 2). (As a reminder, sentence 7 either supported or refuted the implied trait, except in control contexts, for which this sentence continued a nontrait description.) Again, we observed only a main effect of story context $\left[F_{1}(3,189)=15.27\right.$, $M S_{\mathrm{e}}=371,035, p<.001 ; F_{2}(3,69)=3.41, M S_{\mathrm{e}}=$ $627,440, p<.05]$. Planned contrasts revealed some form of difference across all story contexts. Participants took longer to read refutation with explanation contexts than to read trait contexts [a 497-msec difference: $F_{1}(1,63)=$ 45.53, $M S_{\mathrm{e}}=347,666, p<.001 ; F_{2}(1,23)=11.00$, $\left.M S_{\mathrm{e}}=538,836, p<.01\right]$, control contexts [a 291-msec difference: $F_{1}(1,63)=13.49, M S_{\mathrm{e}}=401,613, p<.001$; $\left.F_{2}(1,23)=1.87, p>.1\right]$, and simple refutation contexts [a 159-msec difference: $F_{1}(1,63)=6.91, M S_{\mathrm{e}}=236,769$, $\left.p<.05 ; F_{2}(1,23)=1.14, p>.1\right]$. Participants took longer to read simple refutation than to read trait contexts [a 338-msec difference: $F_{1}(1,63)=21.16, M S_{\mathrm{e}}=344,428$, $\left.p<.001 ; F_{2}(1,23)=11.30, M S_{\mathrm{e}}=252,621, p<.05\right]$ but not controls (both $F_{\mathrm{s}}<2.7$ ). Finally, reading times were longer for control than for trait contexts [a 206-msec difference: $F_{1}(1,63)=5.70, M S_{\mathrm{e}}=478,435, p<.05$; $\left.F_{2}(1,23)=1.59, p>.1\right]$. These reading times reveal that, in general, readers noticed discrepancies between behavioral evidence and refutations.

The reading time patterns in Experiment 2 were in line with our predictions. First, readers had difficulty integrating information into memory when it was inconsistent with a previously encoded trait model. For trait contexts, it took participants longer to read trait-inconsistent outcomes than to read consistent outcomes; for control contexts lacking trait information, there was no difference in reading times. Secondly, the type of refutation that participants read had a differing impact on moment-by-moment comprehension. When refutations contained an explanation, readers took longer to read formerly trait-inconsistent outcomes than to read trait-consistent outcomes. In contrast, this pattern was not obtained following simple refutations; reading times for outcomes that followed simple refutations resembled the pattern obtained for trait contexts. Overall, these results suggest that readers can spontaneously revise their expectations for future narrative events, if provided with appropriately informative refutations. These refutations included detail that specifically called into question the causal appropriateness of trait inferences.

As in Experiment 1, participants took longer to read sentences that refuted potential traits than to read statements that supported them. Even without instructions to carefully monitor the unfolding story, readers appeared to detect discrepancies between trait evidence and the refutations that immediately followed. Despite seeming to notice this though, readers tended to revise their models only when refutations included explanations that explicitly described why that model was inappropriate; in other words, detection was not enough to result in revision. Presumably, the explanations provided in a refutation can help readers both notice a discrepancy and - more importantly - act on it.

Although the results of Experiment 2, in combination with those of Experiment 1, seem to suggest that attentional focus can influence the likelihood of revision, it should be noted that the dependent variables of the two studies were qualitatively different. In Experiment 1, revision was examined with respect to agreement rates, whereas in Experiment 2 , revision was tested with reading times. Thus, the claim that changes in the likelihood of revision are a function of instructions is potentially confounded by possible differences in the sensitivity of the dependent variables to revision effects. In Experiment 3 we addressed this issue, and further tested the scope of revision, by examining whether instructional demands could influence spontaneous revision across refutation contexts.

\section{EXPERIMENT 3}

In Experiment 3, we examined participants' reading times as a function of story contexts under conditions designed to encourage careful consideration of narrative events. To do this we included instructions that asked participants to anticipate how the stories would unfold. This experiment allowed for a more direct comparison of the impact of instructions on reader revision with respect to the results of Experiment 2. If instructions direct readers' attention toward noticing and, more importantly, acting upon potential trait discrepancies, we expected longer reading times for trait-consistent than for traitinconsistent outcomes following both simple refutations and refutations with explanations (as in Experiment 1). If, however, instructions are not useful in this regard, we expected to observe this pattern only for cases in which refutations provide sufficient explanation to suggest the need for revision (i.e., refutations with explanations, as in Experiment 2).

\section{Method}

Participants. Fifty-nine Northwestern University undergraduates, all native speakers of English, completed this study for course credit. Three participants' data were eliminated for failure to follow instructions.

Apparatus. The apparatus was identical to that used in Experiments 1 and 2 .

Materials and Design. We used the same stories, outcome sentences, comprehension questions, and fillers as in Experiments 1 
and 2. The design used a Latin square to distribute items in a fashion identical to that used in Experiments 1 and 2.

Procedure. The procedure was identical to Experiment 2, with the following modification: Before beginning, participants were asked to carefully consider the likelihood of future narrative events. The instructions for Experiment 3 were based on those included in previous studies requiring participants to track story events and to anticipate future narrative situations during reading (Albrecht, O’Brien, Mason, \& Myers, 1995; Zwaan \& van Oostendorp, 1993). The instructions explicitly stated:

As you read each story, be sure to pay attention to the information that is presented and think about what will happen next in the narrative. Carefully follow the main character and the story events, anticipating how things will turn out. Make certain to pay attention to what happens, and what you think will happen next, as the stories unfold. Please make sure to do this as you read each story.

Participants were reminded of the instructions after the conclusion of the practice session, and approximately halfway through the experimental session.

\section{Results and Discussion}

Table 4 presents the mean reading times for outcome sentences in Experiment 3. As with Experiments 1 and 2, we eliminated reading times falling more than $2.5 \mathrm{SDs}$ above the mean for each participant, resulting in a loss of $2.28 \%$ of the data.

We expected that participants' reading times for story outcomes would, again, be influenced by story contexts. This interaction was significant by participants and marginal by items $\left[F_{1}(3,165)=6.13, M S_{\mathrm{e}}=245,599, p<\right.$ $\left..005 ; F_{2}(3,69)=2.36, M S_{\mathrm{e}}=225,914, p=.079\right]$; no main effects were significant (all $F \mathrm{~s}<1.9$ ). We conducted planned contrasts for each condition to examine outcome reading times as a function of story contexts. Following trait contexts, participants took $158 \mathrm{msec}$ longer to read trait-inconsistent than to read trait-consistent outcomes, marginal by participants only $\left[F_{1}(1,55)=3.18, M S_{\mathrm{e}}=\right.$ $\left.443,529, p=.080 ; F_{2}<1.1\right]$. For control contexts containing no trait information, this difference was $117 \mathrm{msec}$ and not significant (both $F_{\mathrm{s}}<1.7$ ). This pattern is consistent with those obtained in Experiments 1 and 2. Analogous planned contrasts were conducted for the refutation contexts, revealing evidence of updating across both conditions. Following simple refutations, participants took $310 \mathrm{msec}$ longer to read trait-consistent than to read traitinconsistent outcomes, significant by participants and marginal by items $\left[F_{1}(1,55)=8.53, M S_{\mathrm{e}}=633,258, p<\right.$ $\left..05 ; F_{2}(1,23)=2.98, M S_{\mathrm{e}}=512,509, p=.097\right]$. Following refutations with explanations, participants similarly took 199 msec longer to read trait-consistent than to read trait-inconsistent outcomes, significant by participants only $\left[F_{1}(1,55)=6.12, M S_{\mathrm{e}}=363,602, p<.05 ; F_{2}<\right.$ 1.7]. Note that the direction of reading time patterns obtained for both refutation contexts runs opposite to that obtained for the trait and control contexts.

We compared the difference scores for outcome reading times to further test the impact of the two types of refutations (see Table 4). The 158-msec difference for trait contexts was different from the 199-msec difference for refutation with explanation contexts [significant by participants and marginal by items: $F_{1}(1,55)=7.20, M S_{\mathrm{e}}=997,504$, $\left.p<.05 ; F_{2}(1,23)=3.08, M S_{\mathrm{e}}=913,521, p=.093\right]$, and the 310 -msec difference for simple refutation contexts [significant by participants and marginal by items: $F_{1}(1,55)=$ $10.45, M S_{\mathrm{e}}=1,180,443, p<.01 ; F_{2}(1,23)=3.13, M S_{\mathrm{e}}=$ $1,269,321, p=.090]$. The difference scores for simple refutation and refutations with explanation contexts were not statistically different (both $F_{\mathbf{S}}<1$ ). The results suggest that, with instructions to carefully consider the story events, participants revised their expectations following either type of refutation. As a final analysis of these effects, the differences compared with zero were significant for the refutation-with-explanation comparison [by participants only: $\left.F_{1}(1,55)=6.12, M S_{\mathrm{e}}=363,602, p<.05 ; F_{2}<1.7\right]$, the simple refutation comparison [by participants and marginal by items: $F_{1}(1,55)=8.53, M S_{\mathrm{e}}=633,258, p<.01$; $\left.F_{2}(1,23)=2.98, M S_{\mathrm{e}}=512,509, p=.097\right]$, and the trait comparison [marginal by participants only: $F_{1}(1,55)=$ $\left.3.18, M S_{\mathrm{e}}=443,529, p=.080 ; F_{2}<1.1\right]$, but not for the control comparison (both $F_{\mathrm{S}}<1.7$ ).

We concluded by examining reading times for sentence 7, again, as an indication of whether readers noticed discrepancies as a function of the unfolding refutations (see Table 2). As in Experiments 1 and 2, we observed only a main effect of story context $\left[F_{1}(3,165)=14.55, M S_{\mathrm{e}}=\right.$ $569,016, p<.001 ; F_{2}(3,69)=6.14, M S_{\mathrm{e}}=620,650, p<$ $.01]$. Planned contrasts revealed that participants took longer to read refutation with explanation than to read trait [a 571-msec difference: $F_{1}(1,55)=63.89, M S_{\mathrm{e}}=$ $284,992, p<.001 ; F_{2}(1,23)=12.54, M S_{\mathrm{e}}=693,304$, $p<.01$ ] and control contexts [a 395-msec difference: $F_{1}(1,55)=10.70, M S_{\mathrm{e}}=813,418, p<.01 ; F_{2}(1,23)=$ 4.97, $\left.M S_{\mathrm{e}}=853,842, p<.05\right]$; however, they took an

Table 4

Mean Reading Times (in Milliseconds), With Standard Deviations, for Outcome Sentences in Experiment 3

\begin{tabular}{|c|c|c|c|c|c|c|c|c|}
\hline \multirow[b]{3}{*}{ Outcome } & \multicolumn{8}{|c|}{ Story Context } \\
\hline & \multicolumn{2}{|c|}{$\begin{array}{c}\text { Trait } \\
\text { Context }\end{array}$} & \multicolumn{2}{|c|}{$\begin{array}{c}\text { Simple } \\
\text { Refutation }\end{array}$} & \multicolumn{2}{|c|}{$\begin{array}{l}\text { Refutation + } \\
\text { Explanation }\end{array}$} & \multicolumn{2}{|c|}{$\begin{array}{l}\text { Control } \\
\text { Context }\end{array}$} \\
\hline & $M$ & $S D$ & $M$ & $S D$ & $M$ & $S D$ & $M$ & $S D$ \\
\hline Trait consistent & 2,296 & 873 & 2,635 & 1,215 & 2,512 & 869 & 2,293 & 773 \\
\hline Trait inconsistent & 2,454 & 868 & 2,325 & 778 & 2,313 & 769 & 2,410 & 731 \\
\hline Mean & 2,345 & & 2,480 & & 2,413 & & 2,352 & \\
\hline Difference score & -158 & & 310 & & 199 & & -117 & \\
\hline
\end{tabular}

Note-Difference scores were computed by subtracting trait-inconsistent reading times from trait-consistent reading times. 
equivalent amount of time to read refutation with explanation and simple refutation contexts (a nonsignificant 60-msec difference: both $F_{\mathrm{s}}<1$ ). Participants also took longer to read simple refutation than to read trait contexts [a 511-msec difference: $F_{1}(1,55)=32.02, M S_{\mathrm{e}}=$ $455,111, p<.001 ; F_{2}(1,23)=15.44, M S_{\mathrm{e}}=408,039$, $p<.005$ ] and control contexts [a 335-msec difference: $F_{1}(1,55)=10.00, M S_{\mathrm{e}}=625,345, p<.005 ; F_{2}(1,23)=$ $\left.3.84, M S_{\mathrm{e}}=684,618, p=.062\right]$. Finally, reading times were equivalent for control and trait contexts (a nonsignificant 176-msec difference: both $F \mathrm{~s}<2.3$ ). Overall, participants' increased reading times to sentence 7 in both refutation contexts suggests that they noticed the discrepancies offered by those refutations.

The results of Experiment 3 were in line with, and extended, the previous results. Following trait contexts but not control contexts, participants took longer to read trait-inconsistent outcomes than to read trait-consistent outcomes. In addition, the impact of refutations increased as a function of participants' instructions to carefully consider the unfolding plots of the stories. The inclusion of instructions to anticipate narrative events resulted in readers' revision of trait models following both simple refutations and refutations with explanations. Recall that, in Experiment 2, the lack of any instruction to carefully monitor the stories limited updating effects to refutations that included explanations. Taken together, the results of Experiments 2 and 3 support the hypothesis that task instructions can guide readers' focus on story content and improve the likelihood of revision.

Consistent with Experiments 1 and 2, readers noticed the discrepancies suggested by statements that refuted prior behavioral evidence for traits. Recall that in Experiment 2, although readers appeared to detect these discrepancies they did not necessarily revise their trait models as a function of such detection. In Experiment 3, instructions to carefully consider the appropriateness of story outcomes likely enhanced the probability of readers acting on such contradictory information. These types of instruction could exert their impact by fostering a more evaluative approach to processing unfolding statements in the narratives (e.g., Singer, 2006).

\section{GENERAL DISCUSSION}

The purpose of this study was to investigate some of the conditions under which readers revise their trait-based expectations during narrative comprehension. In three experiments, we tested the contributions of task instructions and refutation content to readers' updating of memory for story characters. In Experiment 1, participants were given explicit instructions to judge the appropriateness of story outcomes; these instructions were provided to help focus readers' efforts on tracking the unfolding plot of those stories. Readers tended to revise their trait models with this task, whether refutations included explanations or not. In Experiment 2, we examined whether readers would revise their models without explicit instruction. Reading time analyses suggested that readers revised their models when refutations included causal explanations; in contrast, sim- ple refutations no longer led to clear revision. In Experiment 3, instructions were included in the task, but an explicit judgment activity was not. Reading times for story outcomes revealed that, as in Experiment 1, participants updated following both refutations with explanations and simple refutation contexts. Thus, the goals of a reading task and the content of refutation materials both contribute to the likelihood of successful revision.

The results of Experiments 2 and 3 provide comparative evidence of the utility of goals and content on revision processes, measured during moment-by-moment reading. However, it is important to note that the item analyses in those experiments at times failed to reach significance when the analyses by participants were significant. We attempted to control basic factors across items such as outcome length (as previously described) and syllable counts for outcomes (trait-consistent $M=13.875$; traitinconsistent $M=14.25 ; F<1$ ). In addition, we also tried to control for narrative factors that might instantiate variability in the experimental materials. For example, temporal discontinuities can influence reading times (e.g., Rapp \& Gerrig; 2002 Zwaan, 1996), so story outcomes were designed to always follow preceding events within a brief time interval. However, we could not control the degree to which the story outcomes might be equivalently inferred across stories, the types of inferences readers might construct across the stories, or how readers' prior knowledge outside the story contexts might influence their inferences and outcome expectations (although, of course, some of these factors were naturally controlled for within stories; also see van den Broek, 1994, for discussion of some of these influences on comprehension). An important tradeoff for this project, as with many other studies, was determining whether to control such factors and constrain the applicability of findings to specific item sets, or to allow for variability in stimuli design. Although the reported analyses in this project may have been a function of such variability, we believe that the overall patterns of results are informative with respect to general properties of reader updating; that is, reader goals and story contexts influence the likelihood that readers will revise their models of characters during moment-by-moment reading.

But to what particular mechanisms might we attribute the underlying effectiveness of these factors on readers' successful revision? In the case of goals, considerable evidence suggests that readers adjust their comprehension activities depending on the purpose of an intended reading experience (e.g., Horiba, 2000; Linderholm \& van den Broek, 2002; van den Broek et al., 2001); that is, readers may focus on different elements of texts, adjust their reading speed, and increase or decrease the degree to which they construct inferences of various types, depending on the purpose of their reading task. For example, Egidi and Gerrig (2006) demonstrated that readers focus on global (i.e., overall story situations) rather than local elements of texts (i.e., current and immediately preceding sentences) when asked to make explicit judgments about the likelihood of story events. We suggest that the degree to which readers focus on local or global elements of texts likely has a direct influence on whether they will successfully or 
unsuccessfully detect and revise their models of characters. For the present study, readers' inclinations to revise were most consistently observed when they were required to consider the appropriateness of text events - a task associated with global processing demands. Thus, successful revision may be more likely when readers consider the overall importance of, and connections among, past and current text elements as they read. We should note that the "think of a title" task included in Experiments 2 and 3 might reasonably be expected to similarly encourage global processing of texts. However, such global processing might be restricted to the point at which readers are asked to construct a title, rather than during the momentby-moment reading of text events. Future studies, to specifically examine the effects of task demands on revision, should include other requirements to evaluate global and local processing activities, both during and after reading.

In the case of text content, various elements of explanatory refutations may have proved beneficial in facilitating revision. The degree to which text elements are perceived by readers as important, salient, or critical for coherence are likely crucial in determining whether readers take stock of contradictions as they read (Otero \& Kintsch, 1992). Revision on the basis of those contradictions may also be a function of whether unfolding text explanations are perceived as valid, reliable, causally relevant, or expected as a function of the preceding story context (Seifert, 2002). For the stories in this study, trait information was intrinsically useful for predicting and comprehending the unfolding plot, and thus readers may have had little difficulty noticing trait-based inconsistencies. Additionally, because trait-instantiating statements were directly followed by refutation material, the immediacy of the refutation may have helped make the discrepancies more salient to readers. There are a priori reasons to suspect that factors such as the text distance between initially presented information and accompanying refutations or qualifications, the quantity of contradictory material, and interactions between text content and readers' goals influence updating during narrative comprehension (e.g., Guéraud et al., 2005; O’Brien et al., 1998; Rapp \& Taylor, 2004). Our results, particularly from Experiment 2, show that these types of factors can separately affect whether readers notice discrepancies and whether readers actually revise as a function of those discrepancies (Otero, 2002).

There is some precedent as to conditions that foster or limit revision during text processing, and updating more generally. Earlier described work by O'Brien and colleagues (1998) has, for example, focused on the effects of qualifications on readers' comprehension of events (e.g., Guéraud et al., 2005; O'Brien et al., 1998). The present study, though, differs from this body of work in three critically important ways, extending investigation of both the scope and influence of factors essential to updating during narrative experiences. First, we focused on readers' updating of encoded information that was not explicitly mentioned in the text. Previous research, when it has employed character models as a means of testing updating, has tended to focus on the explicit characteristics of protagonists (e.g., Albrecht \& O’Brien, 1993; Peracchi \&
O'Brien, 2004). However, studies of memory have shown that, when participants must generate their own items or inferences during reading, information is encoded more strongly than when the same information is explicitly provided during more passive reading (e.g., McNamara \& Kintsch, 1996; Soraci et al., 1994). This has been specifically demonstrated for processes of character-based impression formation (Hamilton, Katz, \& Leirer, 1980). Thus, our study examined conditions under which memory should be particularly resistant to change. Second, we examined how the content of a refutation (i.e., simple refutation vs. refutation with explanation) influences whether readers notice and incorporate new information into memory. Though this issue has been of considerable importance in conceptual change research (see Guzzetti et al., 1993, for a review), prior work in text processing has tended to focus on the quantity of refutation material (e.g., Guéraud et al., 2005) or the location of refutations in text (e.g., Maria \& MacGinitie, 1987) rather than on the quality of a refutation. Third, we employed both overt judgment and reading time methodologies to examine revision-based updating. In previous research, a primary goal has been to determine what is activated during reading (e.g., O'Brien et al., 1998), whereas in this study we assessed reader expectations during reading and what remains after reading has been completed.

This methodological approach was motivated by the fact that reading products (the memory representations that remain following reading experiences) are causally derived from moment-by-moment reading processes (Kintsch, 1988; Trabasso \& Suh, 1993; van den Broek, Young, Tzeng, \& Linderholm, 1999); these processes both guide, and are guided by, texts as they unfold (Rapp \& van den Broek, 2005). Such an approach lends itself to advancing work on revision, and more generally, updating activity. Consider that influential work on updating and revision processes, particularly with respect to effective learning situations, has often focused specifically on offline products. For instance, the degree to which students revise their naive beliefs during conceptual change has been assessed using interviews, tests, recall tasks, and problem-solving activities (Guzzetti et al., 1993). In a similar way, the judgment task in Experiment 1 evaluated the nature of readers' memory representations after a content-based intervention (e.g., a refutation) was provided. Offline measures, however, provide little direct insight into what happens as we read; this limits claims about the mechanisms that underlie updating during reading (Lorch \& van den Broek, 1997). In Experiments 2 and 3, we measured reading times as an online analysis of updating during reading. Online methodologies hold much promise for describing the mechanisms (and their respective time courses) that operate during reading, and for considering conditions that facilitate readers' revision activity (Kendeou \& van den Broek, 2005, 2007).

These methodologies should prove useful for examining other content and goal-based variables that could, theoretically, influence updating. For instance, the intensity or saliency of a particular trait could be manipulated to examine whether such factors affect revision. Consider, 
as an example, character valence: Can the valence of a character trait influence its malleability with respect to particular types of refutations? The present study was not intended specifically as an investigation into whether the valence of character traits (e.g., positive traits like "happy" or negative traits like "sloppy") could influence whether readers update what they know about those characters; the $4 \times 2$ designs of these experiments used 24 experimental stories, which resulted in only 3 observations for each condition, and, therefore, uneven cell distributions for a valence-based analysis. In addition, the magnitude of trait valences was not specifically controlled (i.e., the valences of the traits were not matched across positive and negative cases, and traits within a case likely varied with respect to the intensity of their valences). In future work, we plan to investigate whether positive or negative character traits are differentially influenced by the nature of refutation statements. For example, one might hypothesize, in line with the so-called negativity bias (Fiske, 1980; Rozin \& Royzman, 2001), that negative traits are held more strongly, and thus are less amenable to revision than are positive traits. We also hope to examine whether the likelihood of updating might also be a function of the valence of the trait model suggested in a refutation. For example, our Albert example might include information suggesting not only that Albert is not sloppy, but that he is, in fact, fastidiously neat.

A related, intriguing question for this area of study involves the degree to which authors, rather than readers, are both aware and strategic in their design of refutation materials. Textbook authors likely have a repertoire of writing principles they use to refute misconceptions (e.g., Chambliss, 2002), but do narrative authors possess a similar toolkit? Returning to our earlier example of Sirius Black from Harry Potter and the Prisoner of Azkaban, Rowling (1999) actually uses a variety of methods to convince readers that Sirius is really someone to trust. She explains why Sirius's earlier behaviors could be construed as inappropriate and reveals how missing information might have misrepresented his character. In this study, our refutations implemented similar principles, albeit in a more constrained (i.e., one sentence vs. an entire chapter of a novel) and potentially less entertaining manner. This raises the issue of whether some authors, implementing perhaps an instinctive but nevertheless effective approach, use similar refutation-based methods to ensure that readers account for important changes in unfolding plot. It is worth examining whether the techniques that authors apply in real-world texts can afford insight into the nature of readers' dynamic comprehension activities during reading experiences.

\section{AUTHOR NOTE}

We thank Liz Dean, Holly Harms, Lauren Malone, Kally Nelson, and Sally Polzin for their diligent assistance in data collection. We are also very grateful to Kate Bohn, Irene-Anna Diakidoy, Richard Gerrig, Sid Horton, Albert Katz, Holly Taylor, Mary Jane White, and an anonymous reviewer for their advice and comments on earlier versions of the manuscript. This material is based on work supported by the Institute of Education Sciences Grant R305G040021 and a Faculty Summer Fellowship from the Office of the Dean of the Graduate School at the University of Minnesota awarded to D.N.R., as well as a Research and Development minigrant from the National Science Foundation awarded to D.N.R. and P.K. Correspondence concerning this article should be addressed to D. N. Rapp, School of Education and Social Policy \& Department of Psychology, 2120 Campus Drive, Northwestern University, Evanston, IL 60208 (e-mail: rapp@northwestern.edu).

\section{REFERENCES}

Albrecht, J. E., \& O’Brien, E. J. (1993). Updating a mental model: Maintaining both local and global coherence. Journal of Experimental Psychology: Learning, Memory, \& Cognition, 19, 1061-1069.

Albrecht, J. E., O’Brien, E. J., Mason, R. A., \& Myers, J. L. (1995). The role of perspective in the accessibility of goals during reading. Journal of Experimental Psychology: Learning, Memory, \& Cognition, 21, 364-372.

Allbritton, D. (2004). Strategic production of predictive inferences during comprehension. Discourse Processes, 38, 309-322.

Alvermann, D. E., \& Hague, S. A. (1989). Comprehension of counterintuitive science text: Effects of prior knowledge and text structure. Journal of Educational Research, 82, 197-202.

Alvermann, D. E., Smith, L. C., \& Readence, J. E. (1985). Prior knowledge activation and the comprehension of compatible and incompatible text. Reading Research Quarterly, 20, 420-436.

ANDERson, N. H. (1965). Primacy effects in personality impression formation using a generalized order effect paradigm. Journal of Personality \& Social Psychology, 2, 1-9.

AscH, S. E. (1946). Forming impressions of personality. Journal of Abnormal \& Social Psychology, 41, 1230-1240.

Borkenau, P., \& Liebler, A. (1992). Trait inferences: Sources of validity at zero acquaintance. Journal of Personality \& Social Psychology, 62, 645-657.

Calvo, M. G., Castillo, M. D., \& Schmalhofer, F. (2006). Strategic influence on the time course of predictive inferences in reading. Memory \& Cognition, 34, 68-77.

Chambliss, M. J. (2002). The characteristics of well-designed science textbooks. In J. Otero, J. A. León, \& A. Graesser (Eds.), The psychology of science text comprehension (pp. 51-72). Mahwah, NJ: Erlbaum.

CoOK, A. E., Halleran, J. G., \& O’Brien, E. J. (1998). What is readily available? A memory-based view of text processing. Discourse Processes, 26, 109-129.

DE VeGA, M. (1995). Backward updating of mental models during continuous reading of narratives. Journal of Experimental Psychology: Learning, Memory, \& Cognition, 21, 373-385.

de Vega, M., León, I., \& Diaz, J. M. (1996). The representation of changing emotions in reading comprehension. Cognition \& Emotion, 10, 303-323.

Diakidoy, I. N., Kendeou, P., \& IoAnnides, C. (2003). Reading about energy: The effects of text structure in science learning and conceptual change. Contemporary Educational Psychology, 28, 335-356.

Dole, J. A., \& Sinatra, G. M. (1998). Reconceptualizing change in the cognitive construction of knowledge. Educational Psychologist, 33, 109-128.

EGIDI, G., \& GerRIG, R. J. (2006). Readers' experiences of characters' goals and actions. Journal of Experimental Psychology: Learning, Memory, \& Cognition, 32, 1322-1329.

FISKE, S. T. (1980). Attention and weight in person perception: The impact of negative and extreme behavior. Journal of Personality \& Social Psychology, 38, 889-906.

Fleming, J., \& ARrowood, A. J. (1979). Information processing and the perseverance of discredited self-perceptions. Personality \& Social Psychology Bulletin, 5, 201-205.

Gernsbacher, M. A., Goldsmith, H. H., \& Robertson, R. R. W. (1992). Do readers mentally represent characters' emotional states? Cognition \& Emotion, 6, 89-111.

Gernsbacher, M. A., Hallada, B. M., \& Robertson, R. W. (1998). How automatically do readers infer fictional characters' emotional states? Scientific Studies of Reading, 2, 271-300.

Gerrig, R. J. (1993). Experiencing narrative worlds. New Haven: Yale University Press.

Guéraud, S., Harmon, M. E., \& Peracchi, K. A. (2005). Updating situation models: The memory-based contribution. Discourse Processes, 39, 243-263.

Guzzetti, B. J. (1990). Effects of textual and instructional manipula- 
tions on concept acquisition. Reading Psychology: An International Quarterly, 11, 49-62.

Guzzetti, B. J., Snyder, T. E., Glass, G. V., \& Gamas, W. S. (1993). Promoting conceptual change in science: A comparative meta-analysis of instructional interventions from reading education and science education. Reading Research Quarterly, 28, 117-159.

Guzzetti, B. J., Williams, W. O., Skeels, S. A., \& Wu, S. M. (1997). Influence of text structure on learning counterintuitive physics concepts. Journal of Research in Science Teaching, 34, 701-719.

Hamilton, D. L., Katz, L. B., \& Leirer, V. O. (1980). Cognitive representation of personality impressions: Organizational processes in first impression formation. Journal of Personality \& Social Psychology, 39, $1050-1063$.

HENDRICK, C., \& Costantini, A. F. (1970). Effects of varying trait inconsistency and response requirements on the primary effect of impression formation. Journal of Personality \& Social Psychology, 15, 158-164.

HERTEL, P. T. (1985). Isolation and adaptation in passage memory. Discourse Processes, $\mathbf{8}, 75-90$

Horiba, Y. (2000). Reader control in reading: Effects of language competence, text type, and task. Discourse Processes, 29, 223-267.

Hynd, C., \& Alvermann, D. E. (1986). The role of refutation text in overcoming difficulty with science concepts. Journal of Reading, 29, 440-446.

Hynd, C., \& GuzzetTI, B. J. (1998). When knowledge contradicts intuition: Conceptual change. In C. Hynd (Ed.), Learning from text across conceptual domains (pp. 139-164). Mahwah, NJ: Erlbaum.

JenKINS, J. J. (1979). Four points to remember: A tetrahedral model of memory experiments. In L. S. Cermak \& F. I. M. Craik (Eds.), Levels of processing in human memory (pp. 429-446). Hillsdale, NJ: Erlbaum.

Johnson, H. M., \& Seifert, C. M. (1994). Sources of continued influence effect: When misinformation in memory affects later inferences. Journal of Experimental Psychology: Human Learning \& Memory, 20, 1420-1436.

Johnson, H. M., \& SEIFERT, C. M. (1998). Updating accounts following a correction of misinformation. Journal of Experimental Psychology: Learning, Memory, \& Cognition, 20, 1420-1436.

Johnson, H. M., \& SEIFERT, C. M. (1999). Modifying mental representations: Comprehending corrections. In H. van Oostendorp \& S. R. Goldman (Eds.), The construction of mental representations during reading (pp. 303-318). Hillsdale, NJ: Erlbaum.

Kendeou, P., \& VAN DEN BRoeK, P. (2005). The role of readers' misconceptions on text comprehension. Journal of Educational Psychology, 97, 235-245.

Kendeou, P., \& VAN DEN BRoeK, P. (2007). The effects of prior knowledge and text structure on comprehension processes during reading of scientific texts. Memory \& Cognition, 35, 1567-1577.

KINTSCH, W. (1988). The role of knowledge in discourse comprehension: A construction-integration model. Psychological Review, 95, 163-182.

Kunda, Z., \& ThagaRd, P. (1996). Forming impressions from stereotypes, traits, and behaviors: A parallel-constraint-satisfaction theory. Psychological Review, 103, 284-308.

LiMON, M. L. (2001). On the cognitive conflict as an instructional strategy for conceptual change. Learning \& Instruction, 11, 357-380.

LiNDERHOLM, T., \& VAN DEN BROEK, P. (2002). The effects of reading purpose and working memory capacity on the processing of expository text. Journal of Educational Psychology, 94, 778-784.

LORCH, R. E. J., \& VAN DEN BROEK, P. (1997). Understanding reading comprehension: Current and future contributions to cognitive science. Contemporary Educational Psychology, 22, 213-246.

Magliano, J. P., Trabasso, T., \& Graesser, A. C. (1999). Strategic processes during comprehension. Journal of Educational Psychology, 91, 615-629.

Maria, K., \& MacGinitie, W. (1987). Learning from texts that refute the reader's prior knowledge. Reading Research \& Instruction, 26 222-238.

McKoon, G., \& Ratcliff, R. (1986). Inferences about predictable events. Journal of Experimental Psychology: Learning, Memory, \& Cognition, 12, 82-91.

McNamara, D. S., \& KinTsch, W. (1996). Learning from texts: Effects of prior knowledge and text coherence. Discourse Processes, 22, 247-288

Myers, J. L., \& O'Brien, E. J. (1998). Accessing the discourse representation during reading. Discourse Processes, 26, 131-157.
Newman, L. S., \& Uleman, J. S. (1990). Assimilation and contrast effects in spontaneous trait inference. Personality \& Social Psychology Bulletin, 16, 224-240

O’Brien, E. J., Rizzella, M. L., Albrecht, J. E., \& Halleran, J. G. (1998). Updating a situation model: A memory-based text processing view. Journal of Experimental Psychology: Learning, Memory, \& Cognition, 24, 1200-1210.

OTERo, J. (2002). Noticing and fixing difficulties while understanding science texts. In J. Otero, J. A. León, \& A. C. Graesser (Eds.), The psychology of science text comprehension (pp. 281-307). Mahwah, NJ: Erlbaum.

Otero, J., \& Kintsch, W. (1992). Failures to detect contradictions in text: What readers believe versus what they read. Psychological Science, 3, 229-235.

Peracchi, K. A., \& O'Brien, E. J. (2004). Character profiles and the activation of predictive inferences. Memory \& Cognition, 32, 1044-1052.

PiageT, J. (1957). The child and modern physics. Scientific American, 196, 46-51.

Pintrich, P. R., Marx, R. W., \& Boyle, R. A. (1993). Beyond cold conceptual change: The role of motivational beliefs and classroom contextual factors in the process of conceptual change. Review of Educational Research, 63, 167-199.

Posner, G., Strike, K., Hewson, P., \& Gertzog, W. (1982). Accommodation of a scientific conception: Toward a theory of conceptual change. Science Education, 66, 211-227.

RAPP, D. N., \& GERRIG, R. J. (2002). Readers' reality-driven and plotdriven analyses in narrative comprehension. Memory \& Cognition, 30, 779-788.

RapP, D. N., \& Gerrig, R. J. (2006). Predilections for narrative outcomes: The impact of story contexts and reader preferences. Journal of Memory \& Language, 54, 54-67.

Rapp, D. N., Gerrig, R. J., \& Prentice, D. A. (2001). Readers' traitbased models of characters in narrative comprehension. Journal of Memory \& Language, 45, 737-750.

RAPP, D. N., \& TAYLOR, H. A. (2004). Interactive dimensions in the construction of mental representations for text. Journal of Experimental Psychology: Learning, Memory, \& Cognition, 30, 988-1001.

RaPP, D. N., \& VAN DEN BRoeK, P. (2005). Dynamic text comprehension: An integrative view of reading. Current Directions in Psychological Science, 14, 276-279.

ReEder, G. D., \& CoOvert, M. D. (1986). Revising an impression of morality. Social Cognition, 4, 1-17.

Rowling, J. K. (1999). Harry Potter and the Prisoner of Azkaban. New York: Scholastic Press.

Rozin, P., \& RoYZMAN, E. B. (2001). Negativity bias, negativity dominance, and contagion. Personality \& Social Psychology Review, 5, 296-320.

SEIFERT, C. M. (2002). The continued influence of misinformation in memory: What makes a correction effective. The Psychology of Learning \& Motivation, 41, 265-292.

Seifert, C. M., \& Patalano, A. L. (2001). Opportunism in memory: Preparing for chance encounters. Current Directions in Psychological Science, 10, 198-201.

Sinatra, G. M., \& Pintrich, P. R. (2003). The role of intentions in conceptual change learning. In G. M. Sinatra \& P. R. Pintrich (Eds.), Intentional conceptual change (pp. 1-18). Mahwah, NJ: Erlbaum.

SingER, M. (2006). Verification of text ideas during reading. Journal of Memory \& Language, 54, 574-591.

Singer, M., Graesser, A. C., \& Trabasso, T. (1994). Minimal or global inference during reading. Journal of Memory \& Language, 33, 421441

Soraci, S. A., Jr., Franks, J. J., Bransford, J. D., Chechile, R. A., BELLI, R. F., CARR, M., \& CARLIN, M. (1994). Incongruous item generation effects: A multiple-cue perspective. Journal of Experimental Psychology: Learning, Memory, \& Cognition, 20, 67-78.

Trabasso, T., \& SUH, S. (1993). Understanding text: Achieving explanatory coherence through on-line inferences and mental operations in working memory. Discourse Processes, 16, 3-34.

Trabasso, T., \& van den Broek, P. (1985). Causal thinking and the representation of narrative events. Journal of Memory \& Language, 24, 612-630.

Uleman, J. S., Hon, A., Roman, R. J., \& Moskowitz, G. B. (1996). On-line evidence for spontaneous trait inferences at encoding. Personality \& Social Psychology Bulletin, 22, 377-394. 
VAN DEN Broek, P. (1994). Comprehension and memory of narrative texts. In M. A. Gernsbacher (Ed.), Handbook of psycholinguistics (pp. 539-588). London: Academic Press.

VAN DEN Broek, P., Lorch, R. F., Linderholm, T., \& Gustafson, M. (2001). The effects of readers' goals on inference generation and memory for texts. Memory \& Cognition, 29, 1081-1087.

VAN DEN Broek, P., RapP, D. N., \& KendeOU, P. (2005). Integrating memory-based and constructionist processes in accounts of reading comprehension. Discourse Processes, 39, 299-316.

van den Broek, P., Young, M., Tzeng, Y., \& Linderholm, T. (1999). The landscape model of reading. In H. van Oostendorp \& S. R. Goldman (Eds.), The construction of mental representations during reading (pp. 71-98). Mahwah, NJ: Erlbaum.

VAN OOSTENDORP, H., \& BonebaKKer, C. (1999). Difficulties in updating mental representations during reading news reports. In $\mathrm{H}$. van Oostendorp \& S. R. Goldman (Eds.), The construction of mental representations during reading (pp. 319-339). Hillsdale, NJ: Erlbaum

Vosniadou, S. (2003). Exploring the relationships between conceptual change and intentional learning. In G. M. Sinatra \& P. R. Printrich (Eds.), Intentional conceptual change (pp. 377-406). Mahwah, NJ: Erlbaum.

Wilkes, A. L., \& Leatherbarrow, M. (1988). Editing episodic mem- ory following the identification of error. Quarterly Journal of Experimental Psychology, 40A, 361-387.

Winter, L., \& UlEMAN, J. S. (1984). When are social judgments made? Evidence for the spontaneousness of trait inferences. Journal of Personality \& Social Psychology, 47, 237-252.

YBARRA, O. (2001). When first impressions don't last: The role of isolation and adaptation processes in the revision of evaluative impressions. Social Cognition, 19, 491-520.

Ybarra, O., Schaberg, L., \& Keiper, S. (1999). Favorable and unfavorable target expectancies and social information processing. Journal of Personality \& Social Psychology, 77, 698-709.

ZwaAn, R. A. (1996). Processing narrative time shifts. Journal of Experimental Psychology: Learning, Memory, \& Cognition, 22, 1196-1207.

ZwaAn, R. A., \& Madden, C. J. (2004). Updating situation models. Journal of Experimental Psychology: Learning, Memory, \& Cognition, 30, 283-288.

ZWAan, R. A., \& RadVAnsky, G. A. (1998). Situation models in language comprehension and memory. Psychological Bulletin, 123, 162-185.

ZWAan, R. A., \& VAN OOSTENDORP, H. (1993). Do readers construct spatial representations in naturalistic story comprehension? Discourse Processes, 16, 125-143.

\section{APPENDIX \\ Sample Story and Outcomes From Experiments 1, 2, and 3 \\ Episode 1 (Sloppy) \\ Albert was listening to the radio. He had finished getting ready to meet his friends at the movies. They were going to see a new comedy that was getting rave reviews. He pulled a sweater over his head. Then he began to look for his shoes.}

\section{Trait Context}

They were buried under old candy wrappers, crumpled magazines, and some dirty laundry. Albert didn't care about keeping his room clean, and this is how it usually would look.

\section{Simple Refutation Context}

They were buried under old candy wrappers, crumpled magazines, and some dirty laundry. Albert cared about the condition of his room, even though it currently wasn't up to par.

\section{Refutation With Explanation Context}

They were buried under old candy wrappers, crumpled magazines, and some dirty laundry. Albert cared about the condition of his room, but had only moved into the apartment yesterday.

\section{Control Context}

Albert's friends had suggested meeting outside the pizzeria adjacent to the movie theater. The pizzeria was one of their favorite spots in town, and the movie theater was too.

\section{Episode 2}

Albert had to take the bus to go to the movies. He bought a newspaper to read during the ride to the theater. Albert had finished leafing through the paper when his stop was announced. Albert put the newspaper on the seat next to him. As he waited for the bus to stop, he noticed a sign asking riders not to leave garbage on the bus.

\section{Outcomes}

Albert ignored the sign and got off the bus. (Trait-consistent)

Albert picked up the newspaper to throw away later. (Trait-inconsistent)

\section{Comprehension Question}

Did Albert read a sign on the bus? (YES)

(Manuscript received June 13, 2006;

revision accepted for publication February 12, 2007.) 